\title{
英国城市绿地标准及其编制步骤
}

\section{A Review of Green Space Standard and Its Preparation in the UK}

邓位 李翔

Deng Wei, Li Xiang

\begin{abstract}
摘要: 首先简要回顾了英国各类城市绿地类型的起源, 继而讨论 绿地标准概念的出现、发展, 以及国家级和地方级的分类标准和 标准的核心内容。就编制绿地标准而言，地方政府须严格遵循五 个步骤, 即: 调查居民所需、评估绿地现状、设定绿地标准、运 用标准和编制绿地标准规划文件。文章以欧洲最“绿”城市谢菲 尔德为例, 讨论了绿地标准的编制过程在实践中的运用。最后小 结指出英国绿地标准及其编制步骤的体系较为成熟, 既严谨又灵 活, 在国家统一框架下又因地制宜, 从而提升了英国城市绿地规 划建设水平, 值得借鉴。

Abstract: The paper reviews the brief history of green space standard system in the UK, including its emerging, development, typology and core issues. As required by relevant national guidance, the local councils have responsibility to produce local green space standards and strategies, in five strict allocated steps: understanding requirements of local residents, assessing current situation, setting local green space standards, applying standards, producing green space standards planning documents. The 'Greenest' city in Europe, Sheffield, is used as a case study, through which the process of producing local green space standards is discussed. The paper concludes that current green space standard system in the UK is mature, which is strict, in terms of national preparation requirements, and flexible to be applied locally. This system has improved the green spaces in cities since it had been introduced, which are valuable referential experience.
\end{abstract}

关键词: 英国城市绿地; 绿地标准; 编制步骤; 绿色基础设施; 谢菲尔德绿地

Keywords: Urban Green Space in the UK; Green Space Standard; Setting Steps; Green Infrastructure;

Green Space of Sheffield

作者: 邓位，博士，AECOM 英国北方设计与规划总部曼彻斯特办 公室, 设计总监。weideng.landscape@gmail.com 李翔, 西南交通大学建筑与艺术学院, 讲师

\section{1 英国城市绿地标准回顾}

\section{1 英国近现代城市各类绿地起源}

1760 年代工业革命开始后, 英国城市建设发展迅速, 到维 多利亚时期（1837-1901 年）城市变得十分拥挤而且污染严重, 市民开始要求提供公共休闲绿地以改善居住环境。1 838 年英国 第一座城市公园博肯汉德公园（Birkenhead Park）在利物浦建 成, 拉开了英国各城市公园和绿地建设的序幕。1898 年, 霍华 德 (Howard E) 在其 “田园城市” 理论中提出将绿地连成网络以 分割各类城市用地 ${ }^{[1]}$, 将绿色廊道的重要性提升到规划层面。然 而绿地的发展被第一次世界大战（1914-1918 年）中断，其间 大量城市绿地被破坏, 居民户外活动场地急剧减少, 许多青少年 由于缺少运动而体质下降。政府担心这可能导致输掉未来的战 争, 因此于 1930 年代开始将绿地的主要功能导向青少年的游戏 和运动场 ${ }^{[2]}$ 。第二次世界大战（1939-1945 年）开始后, 许多城 市绿地又变为粮食生产基地, 这一现象一直延续至 1960 年代中 期, 城市 “菜园” (Allotment) 也因此成为英国重要绿地类型之 一。匀忙的战后重建从 1950 年代开始至 1970 年代结束, 并未改 善城市中心环境, 于是人们开始搬往郊区居住, 政府的建设重心 也转向城市边缘区的乡村公园 (Country Park)。由于缺少政府维 护资金, 大量城市中心绿地逐渐衰败, 至 20 世纪末几乎无人光顾, 成为缺少管理的自然或半自然状态的绿地, 是野生动物的乐园。

回顾历史, 城市绿地在英国出现后, 在各时期发挥了不同的 作用, 其功能和类型逐渐丰富, 成为城市土地用途的重要部分。 1980 年代开始, 英国政府注意到城市中心衰败的问题, 开始结合 城市更新规划对绿地开展大量研究, 以明确城市绿地的现状、功 能、作用、面临的困境和提升目标, 并于 1990 年代开始出台绿 地相关政策, 提出了 “城市绿地标准” (Green Space Standards) 的概念。由于英国是四个国家的联合王国, 先后允许苏格兰 (1997 年)、威尔士（1997 年）和北爱尔兰（2010 年）拥有相对独立的 
政府机构以及规划政策制定和审批权等, 因此它们的规划体 系和绿地标准各不相同 ${ }^{1}$ 。英格兰的城市绿地标准体系发展 时间较长也较为完善, 故本文主要介绍在英国中央政府体制 下英格兰的城市绿地标准。

\section{2 英国城市绿地标准的发展}

1989 年, 英国 “环境部” (Department of Environment) 委托伯明翰大学首次对全英国绿地标准现状进行研究, 发 现：(1) 当时并无全英统一的绿地标准；(2) 政府过于强 调城市边缘区绿地, 忽视了城市中心绿地; (3) 居民更关 心绿地质量而非数量 ${ }^{[3]}$ 。这促成 “英国社区与地方政府部”

(Department of Community and Local Government) 于两年 后首次出台针对英国城市绿地的全国性政策一《规划政策 导则 17 : 开敞空间、运动及休闲空间规划》（以下简称《导 则 17》) ${ }^{[4]}$, 定义城市绿地及类型, 明确绿地标准的核心内容, 并奠定了英国城市绿地标准体系的框架, 即 : 各地方政府 需依据此导则, 结合当地情况制定地方城市绿地标准并施 行。早期的地方绿地标准实例包括：1992 年完成的《新大 伦敦绿地规划》, 更新了城市公园的分级和服务距离标准 ${ }^{[5]}$; 1993 年谢菲尔德政府出台的《公园复兴策略》, 对城市绿地 的功能和价值进行了研究, 并提出了提升城市中心绿地质量 的策略 ${ }^{[6]}$ 。与此同时, 一些专业组织对绿地标准也展开了研 究。例如, 1993 年 “自然英格兰” (Natural England) 在《城 市中的自然空间》报告中明确定义了城市中的 “自然绿地”

(后发展为 “自然与半自然绿地” 类型), 并提出了相关面 积和服务半径标准 ${ }^{[7]}$; 1995 年, 12 个地方政府对绿地标准 落实状况进行了研究, 并发布《公园生活: 城市公园和社会 更新》 ${ }^{[8]}$ 报告, 认为从政策层面仍然对城市绿地重视不足, 对新建项目尤其需要提出更严格的绿地标准和要求。1996年, 英国政府首次提出城市绿地质量标准，设置了积分制的 “绿 色旗帜奖” (The Green Flag Awards) ${ }^{[9]}$, 开始在英格兰和威 尔士施行 (2007 年开始在苏格兰试运行)。简言之, 1990 年 代是英国城市绿地标准的探索时期, 出台了第一批绿地标准 并开始实践运用。

随着 21 世纪初大量城市中心更新项目完成, 英国 “社 区与地方政府部” 再次对绿地进行了一系列研究 ${ }^{[10,11]}$ 。基于 更成熟的认识, 2002 年完成了《导则 17》的修订。为帮助 地方政府理解并执行新导则, 于 2006 年出台了《评估需求 和机遇 : 导则 17 详细指南》 ${ }^{[12]}$ (以下简称《指南》), 明确 地方政府必须严格遵照统一的步骤编制绿地标准, 以保证其 合理、公开、可行。这些要求被写人《地方化法》 ${ }^{[13]}$ (2011 年)
和《国家规划政策框架》 ${ }^{[14]}$ (2012 年), 从而以法律和国家 政策条文加以强化。至此, 英国绿地标准体系基本建立完成。

\section{2 英国城市绿地定义及分类标准}

从英国空间规划体系的角度看, 城市由建筑本身和建 筑之间的户外环境组成, 这些户外环境包括 “绿地” (Green Space) 和 “灰地” (Grey Space)。“绿地” 主要指由可渗透性 自然软质元素覆盖的土地, 以草地、树林等为主, 是人们接 触自然的户外休闲场所; “灰地” 则主要由不可渗透性人工 材料, 如混凝土、沥青等覆盖, 一般为城市提供交通功能, 如道路和广场等 ${ }^{[15]}$ 。其中, 一些广场虽然是 “灰地”, 但由 于提供户外休闲功能, 因此英国规划界常将其与绿地一同讨 论, 统称为 “开敞空间” (Open Space)。其明确定义出现在 1990 年的《城乡规划法》中一一“开敞空间”指公园或花园, 以及用于公众休闲的土地 ${ }^{[16]}$, 强调了公众为使用主体, 休闲 为主要功能的两个特点。《导则 17》将其范畴扩大并指出: “开 敞空间” 不仅要包括用于公众休闲的绿地, 还应包括所有对 公众有价值的户外空间, 如各类水体或运动场地 ${ }^{[4]}$ 。

英国规划界一般认为 “开敞空间” 具有提升社会、环境 和经济等三方面价值 ${ }^{[11]}$ 。绿地可吸引民众前往, 提升地方文 化交流, 从而增加社区认同感。另外, 绿地在为野生生物提 供栖息地的同时, 也为人们提供了观察自然的机会。城市绿 地还可以提供户外健身场所, 改善微气候, 提升人们生活质 量, 从而增加人们对该地区的喜爱程度, 这种积极态度可以 提升该地区的土地价值。高质量的绿地也提升城市街区面貌 和投资环境, 使投资商更有信心, 从而吸引更多资金, 促进 该区域的经济发展。总之, 健康的绿地体系可以使城市人居 环境建设进人可持续发展的良性循环。根据主要功能或空间 形态, 英国社区与地方政府部将开敞空间分为 “城市绿地” 和“市民空间” 两部分, 包括八种类型。从表 1 可以看出, 七种 “城市绿地” 类型涵盖了公众可达的各种 “软质” 空 间, 而 “市民空间” 则主要指用于公众集会或步行交通的硬 质空间。

\section{3 英国城市绿地标准}

\section{1 绿地标准的核心内容}

英国学界认为绿地价值的体现取决于五方面要素 : 多功 能性 (multifunctionality)、首要功能 (primary function)、数 量 (quantity)、可达性 (accessibility) 和质量 (quality) ${ }^{[12]}$ 。“多 功能” 的绿地随处可见, 例如大片草地可以作为儿童足球场, 也是青年晒太阳或老人遛狗的场所。这可以吸引不同人群,

(1) 本文所介绍的规划体系和绿地标准等内容主要适用于英格兰和威尔士地区。为方便阅读, 本文统一用 “英国” 来指称。 
提高绿地使用效率, 却也容易导致该绿地在调查时被多次记 录, 引起混乱。因此, 为避免重复计算, 需明确其 “首要功 能”之后, 再对绿地进行统计, 调查其 “数量”、“可达性” 和 “质量”。

绿地 “数量” 是绿地现状调查和标准制定的出发点, 主 要指需提供某种绿地类型的最低面积要求, 通常表达为每千 人平均拥有的绿地面积。通过 GIS 技术和实地调查结合可得 出客观的绿地面积和边界, 标注于地图后, 作为 “可达性” 调查的基础。“可达性”指从绿地使用者住所到达绿地所需 的距离和时间 ${ }^{[17]}$ 。通过可达性分析, 可以了解哪些地区居民 不能在理想时间内方便到达该绿地, 以便将来进行改善。到 达的方式通常为步行、自行车, 或公共交通等可持续发展方 式。获得准确的可达性数据方法是 : 调查前往某处绿地的所 有居民的距离和所需时间, 以覆盖 $75 \%$ 使用者住所的距离 为服务范围 (Catchment Area), 并在地图上画出。然而, 这 种方式耗费大量人力和时间, 在实践中一般采用更简单的方 法, 即: 将交通时间（如 5、10、15 分钟等）换算成相应步行、 自行车和车行距离, 以该距离为半径沿绿地边界延伸即可画 出服务范围。绿地 “质量” 是第三个重要标准, 其评估受两 方面因素影响 : 一是公众的期望值, 二是绿地自身的设计建 造和维护水平。“数量” “可达性” “质量” 三方面的指标紧 密相关, 决定了绿地对于城市发展和人居环境质量的贡献值, 因此成为英国绿地标准的核心内容。

\section{2 国家级专业组织提出的绿地标准}

在英国, 由于各地方政府现状和历史不同, 设立全英 国统一的绿地 “数量” 和 “可达性” 标准并不合理也不现 实 ${ }^{1181}$ 。因此, 英国城市绿地标准有两个级别, 即国家级和地
方级。国家级的绿地标准一般是在理想状态下的目标, 各地 方政府可将此作为最终目标, 再结合本地情况编制当地切实 可行的绿地标准 ${ }^{[19]}$ 。正因如此, 英国 “环境食品与乡村事务 部” (DEFRA) 认为保护和提升城市绿地的关键在于地方政 府 ${ }^{[20]}$ 。某些绿地类型由于通过规划体系加以控制和落实的可 能性较大, 因此国家级专业组织的标准相对详细, 地方政府 也广泛采用并在编制本地标准时引为参考。这包括 “自然英 格兰” 对 “自然与半自然绿地” 和 “休闲绿地” 提出的数量 和可达性标准 ${ }^{[21]}$, “运动场基金会” 对各类儿童游戏场在数 量和可达性方面详细的指标要求 ${ }^{[22]}$, 以及 “国家菜园及休闲 花园协会”出台的 “菜园” 的面积标准 ${ }^{[231}$, 等。而另一些类 型绿地, 如“公园和花园” “墓园”, 目前并无国家级标准, 地方级绿地标准也更偏向机会性的“项目导向”, 而非 “标 准导向”, 即只在相关建设项目出现后讨论 (表 2)。

与 “数量” 和 “可达性” 以客观数据为基础不同, 绿地 质量标准涉及民众主观预期、设计和长期维护水平, 相对复 杂。一些对绿地质量要求极高的组织（如伦敦的 “皇家公园 机构” [Royal Parks Agency]) 为其所管理维护的公园设置了较 高的质量目标: 要代表英国最好的城市公园 ${ }^{[24]}$ 。部分绿地类 型, 如儿童游戏场和运动设施, 还涉及 “运动场基金会” ${ }^{[25]}$ 的额外要求 : 确保运动设施设计和维护高标准, 以及运动环 境安全 (表 2)。为避免各地的绿地质量标准差异过大, 《导 则 17》建议绿地质量的最低标准应在国家层级确立, 作为 地方政府的参考。“绿色旗帜奖” ${ }^{[26]}$ 施行较早, 运用也最广泛。 它要求民众和专家组对八个绿地质量关键因素（人口欢迎标 示、健康与安全、维护良好并整洁、可持续发展、遗产保护、 社区参与、推广、管理) 评估打分, 按分数高低评奖。由于 许多小型绿地无法提供足够多的绿地元素, 质量很好却无法

\section{表 1 英国城市开敞空间（含城市绿地）分类标准}

\begin{tabular}{|c|c|c|c|}
\hline & 开敞空间分类标准 & 主要功能或目的 & 举例 \\
\hline \multirow{7}{*}{$\begin{array}{l}\text { 城市 } \\
\text { 绿地 }\end{array}$} & 公园和花园 & 公众易达的高质量休闲场所, 可作为社区集会空间 & 城市公园、乡村公园、古典园林等 \\
\hline & 自然及半自然绿地, 包括城市森林 & $\begin{array}{l}\text { 保护野生生物; 提升生物多样性; 提供自然环境教育 } \\
\text { 场所 }\end{array}$ & $\begin{array}{l}\text { 树林、城市森林、灌木林、各类草地、湿地、各类露天水体、 } \\
\text { 废弃地、露天岩石地等 }\end{array}$ \\
\hline & 绿色廊道 & $\begin{array}{l}\text { 步行道、自行车道或马道, 可用于休闲或交通, 以及 } \\
\text { 野生生物迁徙 }\end{array}$ & 河岸、运河岸、自行车道及公众步行道 \\
\hline & 休闲绿地 & $\begin{array}{l}\text { 位于居住或工作场所附近的各类休闲绿地, 可提升生 } \\
\text { 活和工作自然环境质量 }\end{array}$ & 宅旁绿地、小区公众绿地、各类离散的休闲空间 \\
\hline & 儿童及青少年游戏场 & 主要用于儿童和青少年游戏、社交和运动的场所 & 游戏场、滑板场地、户外球类场地, 以及户外自由玩要空间 \\
\hline & 菜园、社区花园及城市农场 & $\begin{array}{l}\text { 向居民提供的自己种植蔬菜瓜果的场地, 是长期可持 } \\
\text { 续发展生活模式和创建健康社区的重要部分 }\end{array}$ & 都市菜园、蔬菜花园 \\
\hline & 墓园、教堂周围墓地, 及其他墓地 & 寄托哀思的安静空间, 可为野生生物提供栖息地 & 各类墓地 \\
\hline $\begin{array}{l}\text { 市民 } \\
\text { 空间 }\end{array}$ & $\begin{array}{l}\text { 市民广场、集市广场及其他专为步 } \\
\text { 行者提供的硬质空间 }\end{array}$ & $\begin{array}{l}\text { 一般在公共建筑外围, 提供步行通道, 以及公共集会 } \\
\text { 空间 }\end{array}$ & 市民广场、集市广场 \\
\hline
\end{tabular}

资料来源 : 参考文献 [4] 
获得高分, 故使得 “绿色旗帜奖” 标准无法被全盘采用。不 过其分类打分评估的模式被地方政府所借鉴，作为制定本地 绿地质量标准的基础。在实践中,大多数地方政府把获得 “绿 色旗帜奖” 作为大型绿地的最高标准, 2013 年英格兰共有 1452 处绿地获奖。

如前所述, 绿地标准核心内容为 “数量” “可达性” “质 量” 三项指标。国家级专业组织提出了部分绿地类型的标准, 但并不强制地方政府采用, 而是作为参考, 以发现各自辖区 与理想状态的差距, 从而设置尽量接近的标准。地方政府有 责任在《指南》要求下, 依据自身情况, 明确当地绿地分类 标准, 完成绿地现状调查评估, 设定可行的绿地标准, 并编 制“绿地策略”加以实现。

\section{4 案例研究 : 谢菲尔德城市绿地标准编制}

位于英国中部的谢菲尔德市 (Sheffield)，因为近代钢铁 工业崛起而发展, 在 20 世纪上半叶受到两次世界大战的破 坏, 战后迅速重建, 其后又经历了 1970-1980 年代的城市 中心萧条, 以及 1990 年代的城市中心复兴, 呈现了典型的 英国现代城市发展历程。谢菲尔德市政府在 1993 年就开始 了城市绿地研究, 是英国早期出台 “绿地策略” 的地方政府 之一, 至今已建立了较为成熟的城市绿地标准, 在绿地标准 编制方面具有代表性。因此, 下文以谢菲尔德市为例, 讨论 英国的地方政府完成城市绿地标准编制的经验和教训。

\section{1 谢菲尔德城市绿地概况及分类}

谢菲尔德市地方政府辖区面积约 $368 \mathrm{~km}^{2}$, 市区人口约 51.6 万。市区绿地类型多样, 其分类标准基本采用了《导则 17》对绿地的分类标准和定义, 仅依据当地绿地现状稍作修 改 : 去除了两类形态松散的类型——“绿色廊道”和 “市民 空间”; 再结合维护模式, 将儿童游戏场和青少年运动场分 成了两类, 即儿童及青少年游戏场, 室外运动场（表 3)。

\section{2 绿地标准编制过程}

谢菲尔德政府严格遵循《指南》要求, 于 2008 年开展 了新一轮的绿地标准编制工作, 完成了规定的五个步骤： （1）调查居民所需；(2) 统计评估绿地现状；（3）设定绿 地标准 ; (4) 运用标准 ; (5) 编制绿地标准文件 ${ }^{[4]}$ 。

第一步, 基于回顾现有绿地标准和政策, 在了解当地居 民对绿地的满意度和期望过程中, 谢菲尔德政府采用了三种 社会调查方法 : 举行公共听证会, 收集了 2594 份意见; 发 放 1.2 万份问卷调查, 随机寄往各社区; 对相关绿地设计和 管理组织举行 “核心组” 访谈。分析调查结果厘清了人们对 城市绿地的使用状况, 包括频率、交通时间、满意度、提升 期望等。

第二步, 结合居民对绿地使用情况，对绿地现状，包 括数量、可达性和质量三项指标进行评估。谢菲尔德政府将 所有面积超过 $0.1 \mathrm{hm}^{2}$ 的公共绿地都纳人统计, 通过 GIS 分

\section{表 2 目前英国国家级专业组织城市绿地标准}

\begin{tabular}{|c|c|c|c|c|c|c|}
\hline 绿地类型 & 数量标准 & \multicolumn{4}{|c|}{ 可达性标准 } & 质量标准 \\
\hline 公园和花园 & \multicolumn{5}{|c|}{ 一般为大型绿地, 取决于建设项目的机会, 目前无国家标准 } & \multirow{4}{*}{$\begin{array}{l}\text { “绿色旗帜 } \\
\text { 奖”标准 }\end{array}$} \\
\hline 自然及半自然绿地 & \multirow{2}{*}{$\begin{array}{l}\text { “自然英格兰”要求：每千人有 } 2 \mathrm{hm}^{2} \text { 绿地 ; 每千人 } \\
\text { 有 } 1 \mathrm{hm}^{2} \text { “地方自然保护区” (Local Nature Reserve) }\end{array}$} & \multirow{2}{*}{\multicolumn{4}{|c|}{$\begin{array}{l}\text { 绿地与住宅最大距离 : } 300 \mathrm{~m} \text { 内应有绿地; } 2 \mathrm{~km} \text { 内应有面积大于 } 20 \mathrm{hm}^{2} \\
\text { 绿地; } 5 \mathrm{~km} \text { 内应有大于 } 100 \mathrm{hm}^{2} \text { 绿地; } 10 \mathrm{~km} \text { 内应有大于 } 500 \mathrm{hm}^{2} \text { 绿地 }\end{array}$}} & \\
\hline 休闲绿地 & & & & & & \\
\hline 绿色廊道 & \multicolumn{5}{|l|}{ 取决于建设项目的机会, 《导则 17》建议不设置国家标准 } & \\
\hline \multirow{8}{*}{ 儿童及青少年游戏场 } & \multirow{8}{*}{$\begin{array}{l}\text { “运动场基金会” 要求: 每千人最少有 } 2.4 \mathrm{hm}^{2} \text { (6 英亩) } \\
\text { 的户外活动空间, 分为两部分一 } 1.6 \mathrm{hm}^{2} \text { (4 英亩) } \\
\text { 户外运动场和 } 0.8 \mathrm{hm}^{2} \text { (2 英亩) 儿童游戏场（分为 } \\
\text { 三个级别 : 门前游戏场 [Local Area for Play]、组团游 } \\
\text { 戏场 [Local Equipped Area for Play] 以及社区游戏场 } \\
\text { [Neighbourhood Area for Play]) }\end{array}$} & \multicolumn{4}{|c|}{ “运动场基金会” 儿童游戏场可达性标准 : } & \multirow{8}{*}{$\begin{array}{l}\text { “运动场基 } \\
\text { 金会” 要 } \\
\text { 求; “绿色 } \\
\text { 旗帜奖” } \\
\text { 标准 }\end{array}$} \\
\hline & & 指标分类 & 门前游戏场 & 组团游戏场 & 社区游戏场 & \\
\hline & & 适合年龄段 & $4 \sim 6$ 岁 & $4 \sim 8$ 岁 & $8 \sim 14$ 岁 & \\
\hline & & 最小活动区面积要求 & $100 \mathrm{~m}^{2}$ & $400 \mathrm{~m}^{2}$ & $1000 \mathrm{~m}^{2}$ & \\
\hline & & 最少游戏设施种类要求 & 无 & 5 种 & 8 种 & \\
\hline & & 最远步行时间 & 1 分钟 & 5 分钟 & 15 分钟 & \\
\hline & & $\begin{array}{l}\text { 最远距离: } \\
\text { 实际路线/直线半径 }\end{array}$ & $100 / 60 \mathrm{~m}$ & $400 / 240 \mathrm{~m}$ & $1000 / 600 \mathrm{~m}$ & \\
\hline & & 活动区距住宅最少距离 & $5 \mathrm{~m}$ & $10 \mathrm{~m}$ & $30 \mathrm{~m}$ & \\
\hline 菜园 & $\begin{array}{l}\text { “国家菜园及休闲花园协会”标准 : 每千户 } 20 \text { 块菜 } \\
\text { 地, 每块菜园平均 } 250 \mathrm{~m}^{2}\end{array}$ & \multicolumn{4}{|c|}{ 取决于建设项目的机会, 目前无可达性国家标准 } & \multirow{3}{*}{$\begin{array}{l}\text { “绿色旗帜 } \\
\text { 奖”标准 }\end{array}$} \\
\hline 墓园 & \multicolumn{5}{|c|}{ 一般只存在于教堂周围, 很难建设新的教堂和墓园, 目前无国家标准, 只要求质量标准 } & \\
\hline 市民空间 & \multicolumn{5}{|l|}{ 很难评估人们对市民空间的使用和需求, 目前无国家标准 } & \\
\hline
\end{tabular}


析和现场确认, 在地图上标明绿地边界、面积和种类等 “数 量” 基础数据。经统计 ${ }^{[27]}$, 谢菲尔德有各类绿地 946 处, 约 $3885 \mathrm{hm}^{2}$, 平均每千人拥有绿地 $7.53 \mathrm{hm}^{2}$ (图 1); 大部分 居民 $(76 \%)$ 满意现有绿地数量, 认为绿地足够。就 “可达 性” 标准而言, 政府采用《导则 17》中建议的 $400 \mathrm{~m}$ (松散 绿地 [Informal Green Space]) 和 $1200 \mathrm{~m}$ (正规绿地 [Formal Green Space]) 服务距离进行评估。调查显示绝大部分居民 (71\% 99\%) 可在 $1200 \mathrm{~m}$ 内到达 “正规绿地”（图 2); 而 对于 “松散绿地”, 仍有接近一半居民（32\% 55\%）不在 $400 \mathrm{~m}$ 服务范围内（图 3)。绿地 “质量” 标准则参考 “绿色 旗帜奖” 将绿地要素划分 (包括可达性、安全性、维护水平,
及对各绿地元素满意度), 再通过社会调查和专家逐项现场 打分评估的办法, 将得分分为六个级别: 很差 (0 15)、差 (16 30)、一般 (31 45)、良好（46 60)、很好（61 75), 极好 (76 以上)。绿地质量调查结果显示各种绿地现状质量 变化较大, 菜园的质量令人堪忧, 室外运动场质量最好（表 3 , 图 2, 图 3)。

基于了解的绿地现状调查数据和居民预期, 进人第三 步一设定绿地标准。考虑到未来人口增长和大部分居民对 绿地数量的满意度, 市政府认为在保持现有数量基础上作 出少量增加应是合理可行的目标。鉴于 “自然英格兰” 2011 年出台的对 “自然及半自然绿地” 的要求, 增加了每千人

\section{表 3 谢菲尔德绿地调查与标准设定}

\begin{tabular}{|c|c|c|c|c|c|c|c|}
\hline & \multirow{2}{*}{$\begin{array}{l}\text { 谢菲尔德 } \\
\text { 绿地类型 }\end{array}$} & \multicolumn{3}{|c|}{ 现状调查 } & \multicolumn{3}{|r|}{ 标准设定 } \\
\hline & & 数量 $\left(\mathrm{hm}^{2}\right)\left(\mathrm{hm}^{2} /\right.$ 千人 $)$ & 可达性 & 平均质量得分 & 数量 & 可达性 & 最低质量得分 \\
\hline \multirow{4}{*}{$\begin{array}{l}\text { 松散 } \\
\text { 绿地 }\end{array}$} & 公园和花园 & $798.05\left(1.55 \mathrm{hm}^{2} / 1000\right)$ & $\begin{array}{l}68 \% \text { 居民在 } 400 \mathrm{~m} \text { 步 } \\
\text { 行距离内 }\end{array}$ & 良好（46 分） & 保持原状 & \multirow{4}{*}{$\begin{array}{l}\text { 所有居民 } \\
\text { 在 } 400 \mathrm{~m} \\
\text { 内步行距 } \\
\text { 离内 }\end{array}$} & $\begin{array}{l}\text { 所有公园达“良好” (46 分) 以上; } \\
\text { 大型公园达 “很好” (61 分) }\end{array}$ \\
\hline & $\begin{array}{l}\text { 自然及半自然 } \\
\text { 绿地 }\end{array}$ & $1567.34\left(3.04 \mathrm{hm}^{2} / 1000\right)$ & $\begin{array}{l}59 \% \text { 居民在 } 400 \mathrm{~m} \text { 步 } \\
\text { 行距离内 }\end{array}$ & 一般 (32 分) & $\begin{array}{l}\text { 保持原状 ; 确保 } \\
\text { 每千人 } 1 \mathrm{hm}^{2} \text { “地 } \\
\text { 方自然保护区” }\end{array}$ & & $\begin{array}{l}\text { 所有绿地达到“良好” (46 分) ; “地 } \\
\text { 方自然保护区” 需达 “很好”(61 分) }\end{array}$ \\
\hline & 休闲绿地 & $289.76\left(0.56 \mathrm{hm}^{2} / 1000\right)$ & $\begin{array}{l}66 \% \text { 居民在 } 400 \mathrm{~m} \text { 步 } \\
\text { 行距离内 }\end{array}$ & 一般 (41 分) & 保持原状 & & 所有绿地达 “良好” (46 分) 以上 \\
\hline & $\begin{array}{l}\text { 儿童及青少年 } \\
\text { 游戏场 }\end{array}$ & $15.64\left(0.16 \mathrm{hm}^{2} / 1000\right)$ & $\begin{array}{l}45 \% \text { 居民在 } 400 \mathrm{~m} \text { 步 } \\
\text { 行距离内 }\end{array}$ & 一般（31 分） & 保持原状 & & 所有场地达 “良好” (46 分) 以上 \\
\hline \multirow{3}{*}{$\begin{array}{l}\text { 正规 } \\
\text { 绿地 }\end{array}$} & 室外运动场 & $\begin{array}{l}922.5\left(1.12 \mathrm{hm}^{2} / 1000, \text { 不 }\right. \\
\text { 含高尔夫球场 })\end{array}$ & $\begin{array}{l}99 \% \text { 居民在 } 1200 \mathrm{~m} \\
\text { 步行距离内 }\end{array}$ & 很好（62 分） & 保持原状 & \multirow{3}{*}{$\begin{array}{l}\text { 所有居民 } \\
\text { 在 } 1200 \mathrm{~m} \\
\text { 内步行距 } \\
\text { 离内 }\end{array}$} & $\begin{array}{l}\text { 所有场地达 “良好”（46 分）; 所有球 } \\
\text { 场活动区达 “很好”（65 分） }\end{array}$ \\
\hline & 菜园及社区花园 & $163.91\left(0.32 \mathrm{hm}^{2} / 1000\right)$ & $\begin{array}{l}85 \% \text { 居民在 } 1200 \mathrm{~m} \\
\text { 步行距离内 }\end{array}$ & 差 (28 分) & 保持原状 & & \begin{tabular}{|l} 
所有菜园达 “良好” (46 分) 以上; \\
所有政府菜园应有自来水和则所设施
\end{tabular} \\
\hline & $\begin{array}{l}\text { 墓园、教堂周围 } \\
\text { 墓地及其他墓地 }\end{array}$ & $141.8\left(0.27 \mathrm{hm}^{2} / 1000\right)$ & $\begin{array}{l}71 \% \text { 居民在 } 1200 \mathrm{~m} \\
\text { 步行距离内 }\end{array}$ & 良好（57 分） & 无标准 & & 所有墓地达 “很好” (61 分) \\
\hline
\end{tabular}

资料来源 : 参考文献 [25]

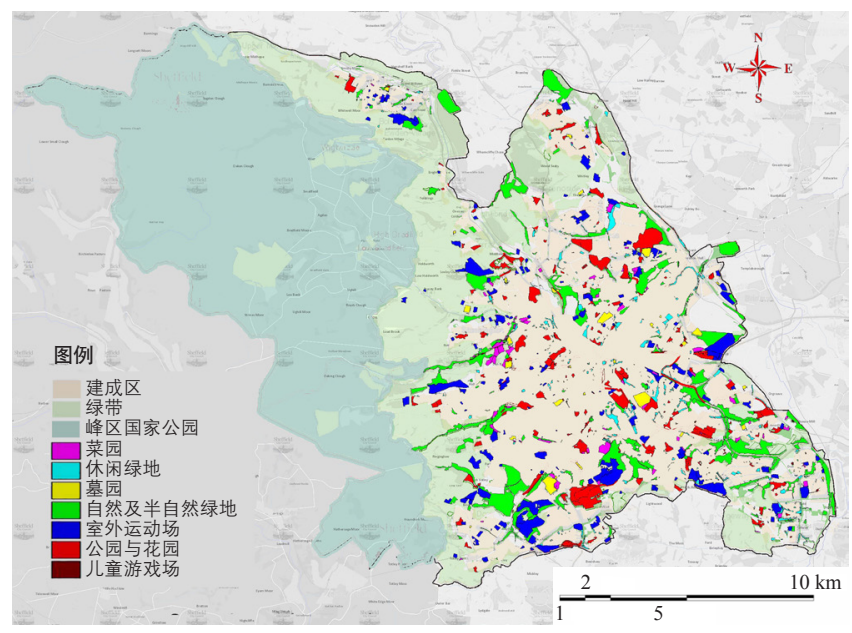

图 1 谢菲尔德城市绿地数量及分类统计 资料来源：作者根据参考文献 [27] 附图制作

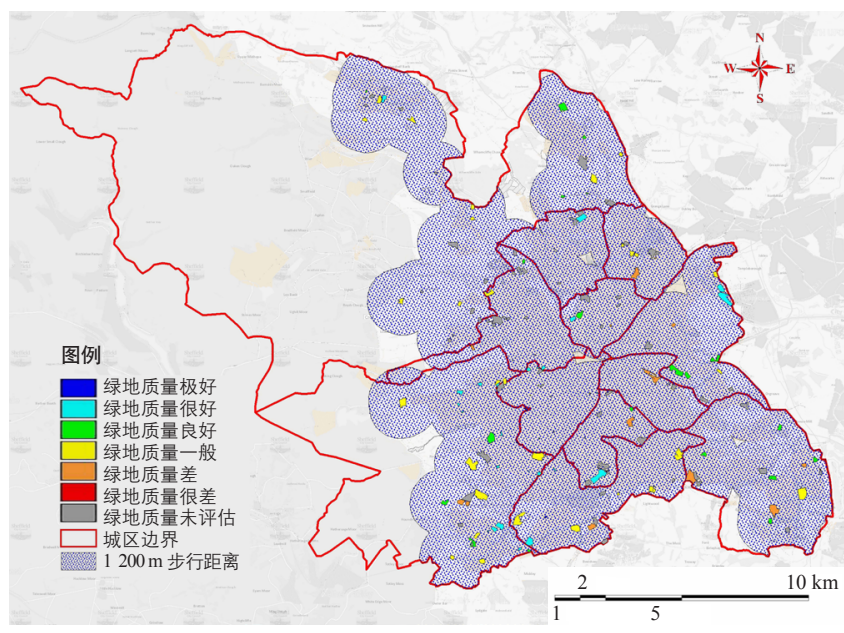

图 2 谢菲尔德室外运动场可达性及质量统计 资料来源 : 同图 1 
$1 \mathrm{hm}^{2}$ “地方自然保护区” 的指标; 而考虑到“墓园” 的恒 定性, 对数量不再作要求; “可达性” 基本沿用《导则 17》 的标准；“质量” 标准要求所有绿地达到“良好”（61 分）以 上 (表 3)。将第三步设定的标准转换到地图上, 就可开展第 四步一运用标准, 分析评估哪些地区缺少绿地, 或绿地质 量需要提升。目前规划的新建绿地很少且只在城市中心（见 图 4 中间极少的红色区域), 转而强调绿廊网络的完整性。

明确绿地标准和需要提升的地区后, 进人最后一步一 编制绿地标准规划文件。市政府根据绿地现状和标准, 针对 各绿地的处理方式制定了几种选择：（1）保持现状；(2) 提 升现状绿地的质量 ; (3) 替换现有绿地至更合理位置, 提高 可达性但数量不变; (4) 新建绿地; (5) 去除多余绿地, 用 于开发建设。一般而言，对于目前质量达“良好”的绿地， 采用“保持原状”, 不需增加绿地面积但也不能减少。另外, 一部分绿地质量达不到 “良好” 要求, 市政府将投人资金, 增加专项绿地预算, 开展绿地更新或提升维护水平, 从而使 其质量得以提升。由于历史原因, 城市一些绿地分布并不平 衡, 市政府将与土地所有者和开发商协商, 通过土地置换的 方式, 将现有多余的绿地用于开发建设, 同时在缺少绿地的 地区建设相同大小的绿地, 从而完成绿地与开发的对等面积 置换。对于所有新建住宅项目, 一般都要按照 “绿地标准” 在基地内新建相应的各类城市绿地，并满足各类型的面积和 可达性要求。最后一种绿地处理方式, 即去除多余的、对当 地绿地网络各功能贡献不大的绿地, 较少施用。绿地置换、 新建绿地和去除绿地三种方式的具体施用一般需等待合适的 开发商和投资者介人，经过该项目所有相关利益团体协商并 达成一致后才能最终实施。

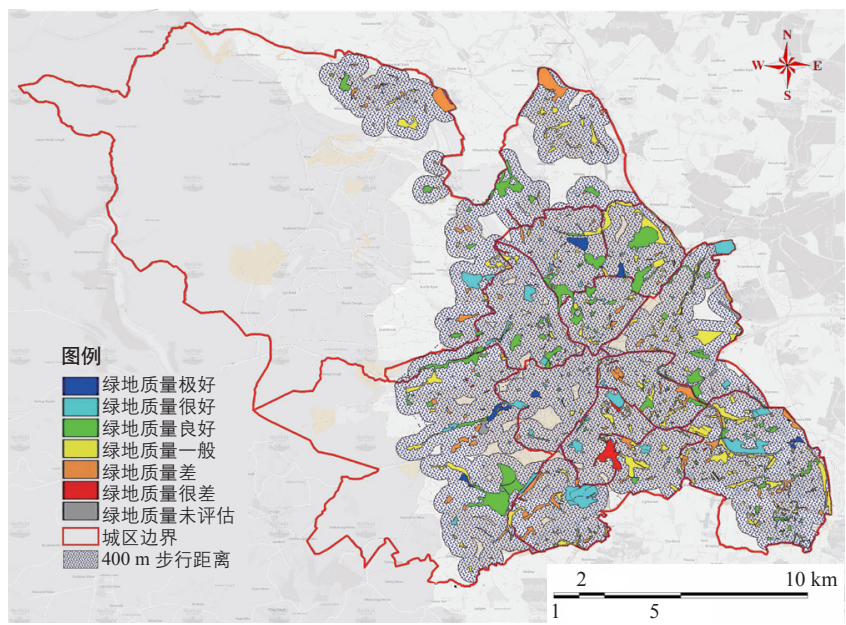

图 3 谢菲尔德松散绿地可达性及质量统计 资料来源 : 同图 1

\section{3 绿地标准成果及小结}

根据《指南》要求, 谢菲尔德将绿地标准写人了《核心 规划》(Core Strategy, 条文编号 CS 45-48), 并画人《规划 地图》(Proposals Map) 成为法定规划文件 ${ }^{[28]}$ 。而更详细的 如何推行绿地标准, 以及落实绿地项目的详细步骤则专门编 制在 “绿地策略” 文件中 ${ }^{[29]}$, 作为法定的“补充性规划文 件” (Supplementary Planning Documents), 在规划审批时具 有法律效力, 从而为未来 20 年提升绿地数量和质量提供了 长期的保证 (图 4)。谢菲尔德由于绿地标准经过多年的发 展, 城市绿地体系已较为完善。如今, 全市拥有 170 处森林 $\left(28 \mathrm{~km}^{2}\right) 、 78$ 处城市公园 $\left(18 \mathrm{~km}^{2}\right)$ 和 10 处公共园林, 有 超过 200 万棵大树, 以及 $11 \mathrm{~km}^{2}$ 水体面积, 加上 $135 \mathrm{~km}^{2}$ 土 地属于 “峰区国家公园”, 约 $61 \%$ 面积被绿地覆盖, 被誉为 欧洲最 “绿”的城市。

\section{5 英国城市绿地标准及其编制经验}

综上可以看出, 英国绿地标准体系具有既严格又灵活的 特点。“严格”体现在两方面：首先, 绿地标准被纳人法定 规划体系, 要求编人 “核心策略” 并出台补充规划文件 “绿 地策略” 加以详细解释, 具有法律效力, 因此在规划项目审 批时绿地指标能得以落实; 其次, 编制绿地标准的步骤严格, 《指南》规定了五个步骤要求地方政府严格遵守, 这样就保 证了绿地标准的客观性、全面性和可行性。英国绿地标准体 系灵活的方面为: 首先, 国家级标准只设定总原则和理想状 态下的目标, 并不强制地方政府执行, 当地可根据实际情况 编制实际可行的标准; 其次, 绿地指标的实际运用较为灵活。 在具体项目中, 根据所在社区的绿地现状, 市政府和开发商

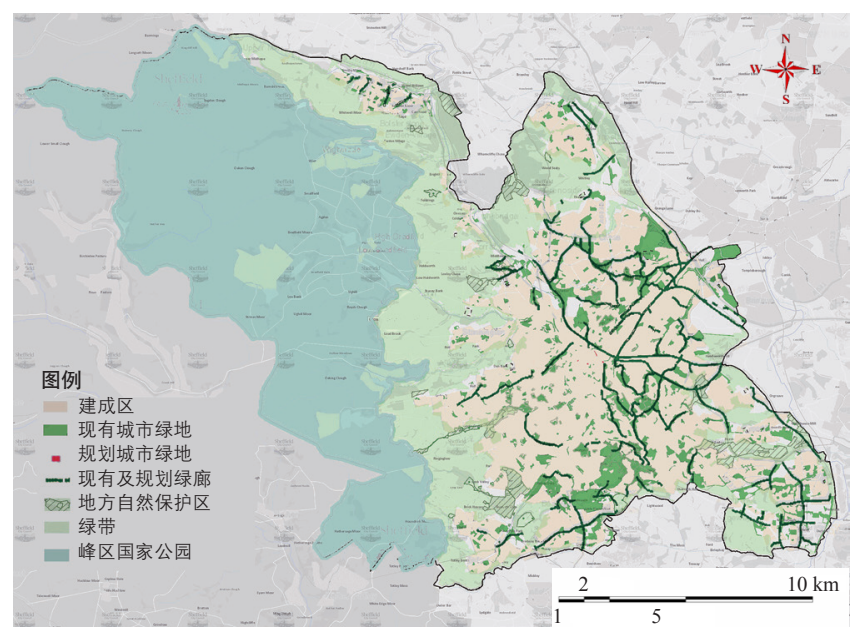

图 4 谢菲尔德城市绿地规划地图

资料来源 : 作者根据市政府在线 “规划地图” 制作, 详见 https://maps.sheffield.gov.uk/ LocalViewExt/Sites/ProposalsMap/ 
需找出提升绿地数量和质量最为合理的方式并达成一致, 从 而做到 “因地制宜”, 使绿地标准落到实处。

当然, 目前英国绿地标准体系仍有不足。第一, 由于 绿地标准只包含公众可以进入的土地, 而同样具有生态休闲 等价值的私人绿地却被忽略, 因此从完整的绿地系统角度 看, 有一定局限性。第二, 目前的绿地标准体系无法覆盖所 有绿地类型, 使得未来城市绿体系统可能出现不平衡发展。 开发商为了保证法律要求的绿地类型数量足够, 会去除未 作要求的类型。例如, 有标准要求的儿童游戏场在未来可能 会增加, 没有标准要求的绿色廊道则可能被减少, 而绿色廊 道对城市绿地网络的连接却极其重要。英国学界已注意到以 上两点 : “自然英格兰” 在《绿色基础设施导则》中指出城 市绿地无论大小都是可持续发展的空间规划的组成部分, 都 可能支持当地的生态系统, 提升自然环境的多功能性, 并成 为应对气候变化的重要手段 ${ }^{[30]}$; “英国皇家风景园林学会”

(Landscape Institute) 认为, 只有当各种绿地相互连接成为 完整的网络时, 才能发挥最大价值 ${ }^{[31]}$, 即 “绿色基础设施”

(Green Infrastructure)。这一概念被《国家规划政策框架》 ${ }^{[14]}$ 支持并要求所有地方政府全盘考量绿地网络, 提供 “绿色基 础设施” 规划, 与绿地标准对应, 以便保证绿地类型长期的 发展平衡。

总体来看, 英国绿地标准体系在规划审批的体系下, 以 国家级专业组织的相关标准为参照, 各地按照统一的编制步 骤, 完成对当地绿地使用现状的调查、分析、评估, 然后根 据需求和发展机会制定合理可行的绿地标准。整个过程充分 考虑了当地的经济、社会和环境条件, 合理严谨, 因此绿地 标准也相对科学可行, 有助于实现长期地逐步提升城市绿地 体系的数量、可达性和质量, 从而促进城市人居环境和可持 续发展, 值得借鉴。Ⓟ

\section{参考文献}

[1] Howard E. Garden Cities of Tomorrow[M]. London: S. Sonnenschein \& Co., Ltd, 1902: 6-25.

[2] Gordon C, Shirley P. All Things to All People, Approaches to Design and Use of Urban Parks Are Evolving[J]. Landscape Design, 2003( 3): 13-17.

[3] Morphet J. Things to all People-MaB Urban Forum. Unpublished Study by Birmingham University for Department of the Environment.[EB/OL]. (1989) [2014-08-06]. http://www.ukmaburbanforum.co.uk/docunents/papers/ allthingldesign.pdf.

[4] DCLG. Planning Policy Guidance 17: Planning for Open Space, Sport and Recreation[R]. London: DCLG, 2006.

[5] London Planning Advisory Committee. Open Space Planning in London[R]. London: LPAC, 1992.

[6] Barber A. Sheffield Parks Regeneration Strategy[R]. Sheffield: Cinteract Consultancy Service, 1993.

[7] Box J, Harrison C. Natural Spaces in Urban Places[J]. Town \& Country Planning, 1993, 62(9): 231-235.

[8] Greenhalgh E, Worpole K. Park Life: Urban Parks and Social Renewal[R].
London: Comedia, 1995.

[9] Department of the Environment Transport \& Regions. Our Towns and Cities: The Future (Urban White Paper)[R]. London: The Stationery Office. 2000 .

[10] Urban Task Force. Towards an Urban Renaissance[M]. London: E. \& F.N. Spon, 1999.

[11] Urban Green Spaces Task Force. Green Spaces Better Places[R]. London: UGSTF, 2002

[12] DCLG. Assessing Needs and Opportunities: A Companion Guide to PPG17[R]. London: DCLG, 2006.

[13] UK Parliament. Localism Act, 2011[EB/OL]. (2012-11-22). http://www. legislation.gov.uk/ukpga/2011/20/contents/enacted.

[14] DCLG. National Planning Policy Framework[R]. London: Department for Communities and Local Government, 2012

[15] Dunnett N, Swanwick C, Woolley H. Improving Urban Parks, Play Areas and Green Spaces[M]. London: DTLR, 2002: 22-23.

[16] UK Parliament. Town and Country Planning Act, 1990[EB/OL]. [2013-1225]. http://www.legislation.gov.uk/ukpga/1990/8/contents.

[17] CABE, Mayor of London. Open Space Strategies Best Practice Guidance. London: Greater London Authority, 2008.

[18] Barber A. Planning Past, Present and Future[M]. London: Urban Parks Forum, 2002.

[19] Scottish Executive Social Research. Minimum Standards for Open Space[M]. Edinburgh: Blackwell's Bookshop, 2005.

[20] DEFRA. The Natural Choice: Securing the Value of Nature[R]. London: DEFRA, 2011

[21] Natural England. 'Nature Nearby' Accessible Natural Greenspace Guidance[R]. London: Natural England, 2011.

[22] Field in Trust. Guidance for Outdoor Sport and Play: Beyond the Six Acre Standard[EB/OL]. [2016-04-25]. http://www.fieldsintrust.org/guidance.

[23] The National Allotment Society. National Allotment Society Policies[EB/ OL]. [2016-04-25]. http://www.nsalg.org.uk/resources-and-downloads/ national-allotment-society-policies/.

[24] Bourn J. The Royal Parks: An Executive Agency[M]. London: National Audit Office, 2004.

[25] Field in Trust. Planning and Design for Outdoor Sports and Play[M]. London: FIT, 2009.

[26] CABE. Raising the Standard: The Green Flag Award Guidance Manual[R]. Liverpool: Blackstrip Design, 2009.

[27] Sheffield City Council. Assessment of Open Space, Outdoor Sports and Recreational Provision for Sheffield[R]. Sheffield: Sheffield City Council, 2008.

[28] Sheffield SDF Team. Sheffield Development Framework: Core Strategy[R]. Sheffield: Sheffield City Council, 2009.

[29] Sheffield City Council. Sheffield's Great Outdoors: Green \& Open Space Strategy 2010-2030 [EB/OL]. [2014-05-20]. https://www.sheffield.gov.uk/out-about/parks-woodlands-countryside/green-and-open-space-strategy.html.

[30] Natural England. Green Infrastructure Guidance (NE176)[R]. Worcester: Natural England, 2009.

[31] Landscape Institute. Green Infrastructures: Connected and Multifunctional Landscape[R]. London: LI, 2009. 